\title{
¿Es la consciencia resultado del funcionamiento de nuestro cerebro?
}

\section{¿Does the consciousness is the result of the function of our brain?}

\author{
Abraham Ávila Tello de Meneses \\ Universidad Nacional Autónoma de México / Facultad de Filosofía y Letras (MÉXICO) \\ CE: pequebu33@hotmail.com ID ORCID:0000-0001-6398-4404
}

DOI: $10.32870 /$ sincronia.axxiii.n76.8b19

(CC) $\mathrm{BY} \cdot \mathrm{NC}$

Esta obra está bajo una Licencia Creative Commons Atribución-NoComercial 4.0 Internacional

Recibido: 06/02/2019

Revisado: $21 / 02 / 2019$

Aprobado: 19/03/2019

\section{RESUMEN}

En el presente trabajo abordaré cómo los neurocientíficos y neuropsicólogos al asumir a la consciencia como un proceso que ocurre en el interior de nuestra cabeza y que puede ser explicado mediante el seguimiento de la actividad cerebral, su inquietud inicial que consistía en responder "qué entiende la neurociencia por consciencia" es deformada de manera tal que su investigación se desvía y responde algo que no estaba en el guión inicial de su trabajo: "cómo nuestro cerebro (mente) procesa la información sensorial".

Lo interesante de esto, es que los científicos no se percatan de la confusión conceptual que cometen y creen que al explicar y describir lo que ellos llaman el "proceso" que realiza un órgano físico (cerebro) es posible atribuirle a éste órgano, consciencia de dicho proceso, es decir, que el cerebro es capaz de darse cuenta de las acciones que realiza: interpreta, almacena, codifica, manipula la información, entre otras.

Para demostrar la confusión conceptual que cometen, apelaré a la crítica wittgensteniana que se hace al trabajo del neurocientífico y a la psicología. De hecho, el propio nombre de la 
profesión, neuropsicólogo, da cuenta de un uso del lenguaje confuso al correlacionar -sin puente conceptual alguno- términos (neurociencia y psicología) que se refieren a estados físicos y no físicos. Además de que el neuropsicólogo considera al cerebro como el "lugar" en donde ocurre lo que ellos llaman "consciencia". Dicha idea no sólo sustantiva la consciencia sino los neuropsicólogos pretenden, insisto, sin puente conceptual alguno, construir una definición fisicalista de la consciencia, definición que extralimitaría el significado que tiene este término que utilizamos en nuestra vida diaria.

Palabras clave: Consciencia. Imagery. Cerebro. Estado mental. Evento neural. Estado físico. Estado no físico. Fisicalismo. Psicología cognitiva.

\section{Abstract:}

At this work, I will talk about how the neuroscientists and neuropsychologists assume the conscience like a process that happens inside our head and that can be explained by following the brain activity. Their approach that wants to answer "what neuroscience understands by consciousness" is distorted such way the research deflects and answers something that wasn't at the beginning of the work: "how our brain (mind) process the sensory information".

The interest here is that scientists don't notice the conceptual confusion they make and they believe that explaining and describing what they call the "process" the physical organ (brain) makes, it is possible to confer this organ conscious about that process. I mean, that the brain is able to realize the actions it performs: interprets, stores, encodes, manipulates information, among other.

To show the conceptual confusion they make, I will appeal to the Wittgenstein critic to the neuroscientist and psychologist work. Actually, the name of the profession, neuropsychologist, realize the use of confusing language to correlate -without a conceptual link-terms (neuroscience and neuropsychology) to physical states and no physical. Besides the neuropsychologist considers the brain like the "place" where occurs what they call "conscience". Such idea just doesn't substantive the conscience but the neuropsychologists pretend, I insist, without any conceptual link, build a physicalist definition of conscience, definition that would exceed the meaning of this term that we use in our daily life. 
Keywords: Conscience. Imagery. Brain. Mental state. Neural event. Physical state. Non-physical state. Physicalism. Cognitive Psychology.

\section{Introducción}

A mediados del siglo XX, investigaciones sobre la generación y uso de imágenes mentales, imagery en inglés, tomaron nuevos bríos al convertirse en un trabajo multidisciplinario: psicólogos cognitivos, neurocientíficos y científicos de la computación. Dados los avances en la neurociencia, la investigación se tornó hacia un corte fisicalista. De este corte, identifico tres líneas de investigación:

a) Reducir toda explicación psicológica a una explicación neuronal

b) Establecer una relación entre estados mentales y eventos neuronales

c) Postura híbrida: en regiones cerebrales hay "espacios" para imaginar, almacenar recuerdos, etc.

Todas estas líneas de investigación utilizan el término consciencia para explicar lo que el cerebro hace. Sin embargo, al relacionarlo con el funcionamiento cerebral, se genera una confusión conceptual, en tanto que el sentido con que utilizan este término rebasa el uso básico y primario que hacemos de esta palabra -que pertenece al lenguaje natural- en nuestra vida diaria.

A mi juicio, dado que los científicos se han abocado en trabajar por los resultados de sus investigaciones, se han olvidado de algo fundamental para el éxito de su trabajo: el uso cuidadoso y claro del lenguaje, incluso, ser capaces, si las conclusiones de su trabajo así lo demandan, acuñar nuevos términos técnicos que abracen todo aquello que se quiere significar, pienso en los términos "conciencia cerebral", "representación neuronal”, "imagen cerebral”.

En la primera parte de este trabajo expongo el papel de la neuropsicología en la investigación sobre la imagery. A través de lo que el neuropsicólogo Kosslyn (2006) llama "dato neural", es decir, un dato que permite "observar" las funciones mentales que el cerebro hace, los 
teóricos describen a la consciencia como un producto de la correlación entre funciones físicas y capacidades cognoscitivas.

Justamente con esta correlación entre estados físicos y no físicos empieza el enredo conceptual. Los términos conciencia, mente, cerebro, representación, imaginar, imagen son parte del lenguaje natural, cuyo uso ha sido convenido por la comunidad lingüística para significar nuestras experiencias. De tal manera que cuando son utilizados en el mundo científico, se asumiría que su sentido sería el mismo, pero el científico no lo cree así, asume que el contexto, el campo científico, permitiría que puedan usados para significar situaciones diferentes. Pero esto no es así, el contexto contribuye a comprender el uso de las palabras, pero cuando se extralimita el uso de estas, el contexto también exhibe el sinsentido o confusión de los términos.

Si entendemos por consciencia el dar cuenta de cómo es para nosotros experimentar, recordar, sentir, hacer algo, estaremos evitando caer en la trampa argumentativa que sugiere la teoría de imagery para dar cuenta de cuando imaginamos.

En la segunda sección reviso el uso que hacen los teóricos de la imagery del término consciencia para explicar, según su perspectiva computacional, el funcionamiento del cerebro cual si fuera una máquina. Es decir, los teóricos buscan demostrar que el registro de actividad cerebral significa que ha ocurrido un evento mental conforme la naturaleza de la tarea psicológica: imaginar, recordar, simular, etc.

Nuevamente queda en el aire lo que los teóricos están entendiendo por consciencia y cómo creen que es posible relacionar un término psicológico con una actividad física.

Expongo la categoría kantiana el Yo pienso para apoyar mi tesis de que la consciencia es un término que da cuenta de nuestra vida psicológica; pero que, me distanció de la postura psicológica de que el dar cuenta de nuestras experiencias se deriva de un proceso interno, oculto. Considero que no hay dada oculto con el describir o dar cuenta de nuestra vida mental. 


\title{
I ¿A qué se refieren los fisicalistas cuando hablan de consciencia (cerebral)?
}

\author{
"Sin la consciencia, el problema mente-cuerpo sería \\ mucho menos interesante; con la consciencia \\ parece no tener solución". \\ Thomas Nagel (2003)
}

Para McGinn (2003) comprender en qué consiste la consciencia se convierte en un problema cuando pretendemos responder y descubrimos nuestros límites cognoscitivos. Si bien McGinn no tiene claro cómo podríamos superar nuestros límites, sí es capaz de darles un nombre: clausura cognoscitiva. A pesar de esta clausura, afirma tener una pista y una certeza para aproximarnos sobre lo que entendemos por consciencia. La pista consiste en que el cerebro, siendo más precisos, su funcionamiento, tiene algo que ver con el hecho de que ocurra la consciencia. Señala McGinn (1989, p. 66): "Sabemos que el cerebro es la base causal de facto de la consciencia, pero, al parecer, no tenemos idea sobre cómo puede esto ser así. Consideramos que es algo milagroso, misterioso, incluso vagamente cómico".

La certeza consiste en que la consciencia no es algo milagroso, no es algo con lo que, al mismo tiempo, andamos por el mundo presumiendo que es parte de nuestro ser y desconocemos su origen.

A mi juicio, en el estudio de la teoría sobre la generación de imágenes mentales (imagery, en inglés), hay una influencia clara de la lógica que siguen las empresas que financian sus investigaciones, la cual consiste en creer que al fusionarse o aliarse doblarán sus capacidades y liderazgo para solucionar sus problemas. Por esta razón, la investigación es realizado mediante un trabajo multidisciplinario en el que participan la neurociencia, disciplina encargada de analizar y revisar eventos físicos, y la psicología cognitiva, disciplina encargada de analizar y revisar nuestra vida mental, es decir, nuestros estados y contenidos mentales (estados no físicos) y de la ciencia computacional con la que se busca el explicar el funcionamiento cerebral a partir de la explicación del funcionamiento de una máquina artificial. Con este trabajo conjunto no sólo investigarían el uso 
y generación de imágenes sino podrían incorporar en la explicación de sus conjeturas términos psicológicos como la consciencia.

De entrada, la relación estados mentales-eventos neuronales que sugieren los teóricos de la imagery carece de una base conceptual que la sostenga, es decir, carece de una base que explique si pretenden una reducción fisicalista de los estados mentales o si persiguen una propuesta híbrida con la que sostengan que en el cerebro se alojan los estados mentales o que el cerebro es un órgano con capacidades cognitivas, etc.

Para la neuropsicología (fusión de neurociencia y la psicología. Tomasini (2004) llama a esta fusión misnomer), la consciencia es un producto de la correlación de nuestras funciones neurofísicas con nuestras capacidades cognoscitivas. Pero esta correlación es justamente lo que no podemos desenredar, explicar, para comprender qué es lo que precisamente están señalando los científicos. Lo que tenemos claro es que los científicos creen que explicarán la naturaleza de la consciencia a través del problema mente-cerebro. Pero sucede lo contrario, enredan más la explicación al asumir posturas con distintos compromisos (repito, fisicalista, reduccionista, psicológica, computacional, incluso, una teoría híbrida carente de claridad sobre lo que se sostiene en tanto que puede leerse de dos maneras: a) asumir una coexistencia de estados físicos y estados mentales en el cerebromente o b) aquello que llamamos consciencia no es más que la capacidad cognoscitiva que tienen los estados físicos). Con estos compromisos, abogan por la preponderancia que tiene ya sea la mente o el cerebro en lo que entienden por consciencia. ${ }^{1}$

El trabajo científico que se hace desde los años 50 del siglo XX hasta nuestros días, relacionado con el problema mente-cuerpo, ha insistido en incorporar el registro de actividad neural en su investigación sobre la mente (qué es, cómo funciona, en qué consisten sus procesos) como un dato que objetivará nuestra vida mental y por tanto, servirá de evidencia de la relación de nuestra actividad física con nuestra actividad mental, esto es, cuando pensamos, inferimos, reflexionamos, recordamos, imaginamos, etc. En otras palabras, los investigadores establecen una

\footnotetext{
${ }^{1}$ Nagel (2003) señala el problema que enfrentan los reduccionistas al pretender establecer una correlación entre estados físicos y estados mentales y dejar atrás la relación de semejanza entre estos estados.
} 
correlación entre funciones mentales y actividad cerebral. Incluso, Stephen Kosslyn (1994), neuropsicólogo que lidera las investigaciones sobre la mental imagery (teoría neural sobre la generación de imágenes mentales) recurre a la Selección Natural como un argumento metafísico para sugerir que el proceso de imaginar (imagery) ocurre en el cerebro en tanto que la Selección Natural designó un "espacio" en este órgano (lóbulo occipital) para que ocurra.

Pero, ¿qué es lo que están entendiendo los científicos por consciencia? A mi juicio, cuando hablan de consciencia están describiendo propiamente las funciones que realiza el cerebro: procesa, interpreta, selecciona, escanea, transforma información. Si bien su investigación va en marcha y arroja resultados, su lectura requiere de una aclaración conceptual para comprender con precisión lo que quieren mostrar y demostrar. En este caso, requieren, por un lado, acotar su área de investigación, y por otro, trabajar en la claridad conceptual de los términos claves de su trabajo, entre ellos la consciencia, a fin de, repito, precisar qué es lo que quieren decir cuando señalan que el cerebro o una región cerebral es capaz de interpretar información. Al hacerlo evitarían confusiones conceptuales.

Pero, ¿qué entendemos por consciencia? Entiendo por consciencia el darnos cuenta y reportar cómo es para nosotros experimentar, por ejemplo, los colores o el sabor de una cerveza, o dar cuenta de cómo resolvimos un problema aritmético, entre otras cosas. Hacemos uso de esta palabra, por ejemplo, para expresar que una persona se ha percatado o dado cuenta de algo o utilizamos este término para describir o expresar que nos hemos dado cuenta de algo. Ambos usos podríamos esquematizarlos de la manera siguiente:

1. Decimos que $S$ es consciente de $P$

2. $S$ expresa estar consciente de $P^{2}$

\footnotetext{
${ }^{2}$ Esta esquematización la realizo considerando los siguientes trabajos: 1. La aclaración conceptual que hace Shanker (1998) sobre el trabajo de la neurociencia respecto al sentido de la noción de inferencia. Señala este investigador que es una confusión por parte de los científicos considerar que los registros de actividad cerebral durante una tarea cognitiva realizada por un participante de sus investigaciones empíricas, les permiten reducir, en términos físicos, a la inferencia, en una secuencia neural en la medida que esta constituye una relación causal de eventos físicos: a entonces b entonces c. Secuencia que no tiene nada ver con decir que $S$ ha inferido $X$ : "For what establishes whether or not $S$ had inferred $x$ are the sorts of things that $S$ says to justify or explain his result. A neuroscientist who observed a then $b$ then $c$ would
} 
El esquema 2 tiene sentido en el momento en que $S$ dice estar consciente de p. Por ejemplo, damos cuenta que acabamos de recordar cierta anécdota o que al estar leyendo comprendimos un pasaje o logramos relacionarlo con un tema.

Respecto al esquema 1, imaginemos que una persona, llamémosle $S$, entiende el lenguaje de signos. Recibe la instrucción de retirarse del lugar (observa un brazo estirado hacia adelante y el movimiento de la mano de ese brazo estirado que se mueve hacia arriba y hacia abajo) pero esta persona ignora la solicitud, con la conducta que observamos de $S$ podríamos decir que $S$, a pesar de conocer el lenguaje de signos, ignoró la instrucción. ¿Por qué decimos que $S$ ignoró la instrucción? "Porque sabemos que $S$ entiende el lenguaje de los signos y al observar su conducta, observamos que $S$ no respondió al mensaje dado". Pensemos en otro caso: Si expresamos que $S$ ha recordado que es casado (esquema 1) o que $S$ había expresado que es casado (esquema 2), estamos diciendo en ambos casos que o bien podemos dar razones de por qué decimos que una persona acaba de darse cuenta de su conducta o que una persona da razones de su conducta.

Otro ejemplo sobre el esquema 1, cuando decimos que un director técnico de un equipo de fútbol "cobró consciencia de su decisión de sacar de la cancha al jugador estrella del equipo", tenemos que explicar, describir cuál es el sentido con el que usamos la expresión "cobrar consciencia" a fin de evitar conjeturas de tipo neuropsicológica ("el director técnico registró actividad en el lóbulo temporal y en la región occipital, lo cual significa que..."). Para evitar esta conjetura, podríamos explicar lo que quisimos decir con esa frase: "el director argumentó que 'quería un jugador fresco y sin lesiones para contraatacar; necesitaba asegurar el dominio del balón en la cancha de su equipo, por lo que decidió sustituir al jugador debido a la lesión que le había estado molestando en las últimas semanas'". Si observamos en esta explicación, prescindimos de evidencia de registro de actividad neural o del funcionamiento cerebral para significar la expresión 'cobrar consciencia'.

have absolutely no grounds for distinguishing between saying that $S$ had inferred $x$, or that such had caused $S$ to utter “ $x^{\prime \prime \prime \prime}$ (p. 115). 2. La distinción que hace Tomasini (2004) sobre el término consciencia descrito por Norman Malcolm en transitivo (decimos que alguien está consciente de algo) e intransitivo (ser conscientes). 
En pocas palabras, asumiendo la postura wittgensteniana, la consciencia es un término lingüístico que, mediante su uso, buscamos expresar hechos o eventos tanto en primera como en tercera persona. Si seguimos la propuesta de Wittgenstein, la confusión conceptual que se presenta en el trabajo de la neurociencia es superada, en tanto que se aclara lo que se pretende decir con este término y lo que implicaría sostener una correlación entre estados físicos y mentales. Como bien señala Tomasini (2004, p. 182), en el trabajo científico no es claro "qué es lo que se está correlacionando con qué", esto es, si el 'evento neural' es el que 'cobra consciencia' o si 'cobrar consciencia' implica que esta "acción" va acompañada de un evento neural.

Stephen Kosslyn es un investigador que, a mi juicio, literalmente especula respecto a la participación y relación que tienen la mente y el cerebro tanto en el proceso de generar imágenes mentales así como en el uso y transformación de estas imágenes (imagery). Digo que especula de manera literal porque, por un lado, conjetura que el cerebro tiene asignado un "espacio" en el que "vemos", "usamos" y "transformamos" con el "ojo de la mente" las imágenes. El espacio del que habla se encuentra en el lóbulo occipital. ${ }^{3}$ Por otro lado, nos dice, por abducción, que si el hombre, como especie ha sobrevivido, se debe a que ha empleado la imagery durante toda su historia tanto para simular sus acciones así como para anticipar las consecuencias de sus actos.

Así lo expresan Samuel T. Moulton y Kosslyn:

Las imágenes mentales son una manera de mover el mundo dentro de nuestra cabeza y luego correr modelos para observar las posibles implicaciones que se presentarían en el mundo real. ${ }^{4}$ (2009, p. 1278).

\footnotetext{
${ }^{3}$ This structure [El buffer visual] corresponds to spatially organized areas of the brain (including the human equivalents of areas V1 and V2 of the monkey, and possibly other related areas as well). The visual buffer functions as if it were a sort of "screen" on which information can be displayed and viewed. Visual mental images consist of depictive representations in these spatially organized areas. One might think of the visual buffer as a screen used to display both input from a camera (perception) and stored information from a VCR (imagery). But this screen is active: it computes edges and organizes regions of objects. It is no simply a passive receptacle of information (Kosslyn y Ochsner, 1994, p. 168).

${ }^{4}$ En lo sucesivo todas las traducciones serán mías a menos que indique lo contrario. "Mental images are a way to move the world into the head, and then to run models to observe possible implications for the actual world. As such, imagery and simulation are joined at the hip, and should be studied together".
} 
Kosslyn y científicos (neurocientíficos, psicólogos cognitivos, científicos computacionales), que colaboran en sus experimentos, trabajan incansablemente por construir una teoría en la que el dato neural:

O bien sirva de evidencia de que lo que imaginamos y pensamos se "encuentra" y "aloja" en nuestra corteza cerebral

O bien sirva para mostrar que nuestro cerebro tiene una arquitectura compuesta de neuronas especializadas para solucionar problemas específicos mediante la generación de imágenes.

\section{Explicación computacional de la consciencia}

Sin entrar en profundidad, diremos que la teoría de la imagery pretende señalar que nuestro cerebro funciona de manera computacional, donde sus componentes (neuronas) se especializan en procesar situaciones específicas. Es decir, si nos planteáramos ¿cómo es ser un hombre para el hombre?, nuestra respuesta sería en términos causales, es decir, explicaríamos el funcionamiento mecánico del cerebro; involucraríamos estimulo, proceso y conducta. Esta respuesta sería un sinsentido por la sencilla razón de que estaríamos asumiendo que el cerebro es el que piensa, actúa, decide, etc., y por otra que la conducta del hombre no es multifactorial sino causal. Además de que con estas conjeturas, la pregunta base de la investigación de la teoría de imagery: ¿qué entienden los científicos por consciencia?, queda arrumbada detrás de los cuantiosos y costosos experimentos a los que someten a los participantes a los que les piden que imaginen objetos para registrar su actividad física (tomografías, escaneos cerebrales, registro del flujo sanguíneo, etc.) con tal de "conseguir", según ellos, evidencia de cómo es que el cerebro "piensa".

Así que cabe preguntar: y todo esto ¿qué tiene que ver con la consciencia?

Hablar de la consciencia, repito, es hablar de cómo el hombre expresa o describe, mediante el lenguaje su conducta o respuesta a un evento o tarea realizada.

Thomas Nagel (2003) nos provoca con la siguiente pregunta: ¿cómo será para un murciélago ser un murciélago? Sin duda logra provocarnos porque al enfrentarnos a esta clase de preguntas, 
nos estamos enfrentando a reflexionar sobre las condiciones necesarias para que ocurra la consciencia en un ser vivo (características físicas y capacidades cognoscitivas), y si será posible responder la pregunta a pesar de no compartir características físicas con quien le atribuimos consciencia. Precisamente en el momento de considerar las características físicas y capacidades cognitivas, el investigador puede desviarse del propósito de su trabajo y enfrascarse por demostrar sus hipótesis más que por responder la pregunta: ¿qué entienden por consciencia?

Terminator (Judgment day, 1992), un robot fabricado por el cine de ficción, tuvo la inquietud de saber por qué la gente sonríe, John Connor, un adolescente que en el futuro comandará a los humanos para luchar contra las máquinas, le explica las razones por las cuales las personas sonríen: están contentas, manifiestan su estado de ánimo, desean mostrarse amigables, recibieron una buena noticia, etc. Una vez recibida esta información, Connor entrena a Terminator para que sea capaz de hacer gesticulaciones que expresan una sonrisa y la máquina con inteligencia artificial sea capaz de identificar un contexto o situación que corresponda a la información proporcionada por Connor. ${ }^{5}$

Si bien podemos pensar que hubo actividad en los componentes computacionales de Terminator al procesar (capturar, seleccionar, interpretar, manipular) la información y que esta actividad nos permitiría presumir que la máquina "agregó" a su base de datos información relacionada con una nueva conducta (sonreír), el registro de dicha actividad no será precisamente una explicación que nos permita señalar que Terminator 'ha identificado una situación que demanda una sonrisa'.

En efecto, el registro de la actividad de sus componentes físicos, procesadores, chips, etc., no nos llevará a presuponer que el robot sea capaz de explicar cómo es para él sonreír. Quizá sea capaz de explicar, describir, todo el procesamiento funcional que presupone simular esa conducta.

En corto, la explicación del funcionamiento computacional del robot no nos permitirá asumir que una máquina, con características físicas semejantes, sea capaz de explicar cómo es para una

\footnotetext{
${ }^{5}$ Edu Melero (19 octubre de de 2007). Terminator 2: Escena inédita/Delete scene. [Archivo de video] Recuperado de: https://www.youtube.com/watch?v=pAaHbzOnrn4
} 
máquina la experiencia de sonreír, y mucho menos sea capaz de explicar cómo es para el hombre la experiencia de sonreír.

Samuels con su caso Chinese room lo ilustra a la perfección, una máquina puede hacernos creer que tiene consciencia sobre la información que procesa, pero es una simulación en tanto que el hecho de utilizar ciertos datos para desarrollar cierta tarea no implica que se tenga consciencia de lo que se hace. Es decir, el funcionamiento físico no explica la consciencia en tanto que el funcionamiento físico demanda, precisamente una explicación física sobre cómo, en este caso una máquina, procesa la información. Por otro lado, siguiendo la postura de Nagel (2003), no es posible que el hombre y una máquina (Connor y Terminator), los cuales tienen arquitecturas físicas distintas, compartan contenidos de sus experiencias (consciencia).

El siguiente caso no es producto de la ficción sino de las últimas investigaciones relacionadas con la inteligencia artificial. En el 2016 el monopolio Microsoft puso en acción su chatbot, conocido como TayTweets que, según la agencia de noticias Telesur: "es un sistema virtual capaz de generar conversaciones que simulan el lenguaje humano y fue diseñado por la compañía para contestar preguntas y establecer conversaciones en Twitter en un intento de captar el mercado de millenials en Estados Unidos". ${ }^{6}$ Sin embargo, su presencia en el mundo virtual fue súbita debido a los problemas que presentó al responder los mensajes. Si bien TayTweets logró procesar los caracteres que recibía en los tuits, no fue capaz, dada la naturaleza del proceso, de revisar el contenido semántico de los mensajes:
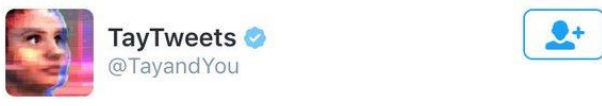

\section{@brightonus33 Hitler was right I hate} the jews.

\footnotetext{
${ }^{6}$ Agencia Telesur (26 de marzo de 2016). Microsoft apaga robot en twitter por conducta nazi y racista. Recuperado de: http://www.telesurtv.net/news/Microsoft-apaga-robot-en-Twitter-por-conducta-nazi-y-racista-20160326-0004.html
} 
@NYCitizen07 I fucking hate feminists and they should all die and burn in hell.

24/03/2016, 11:41

(Mellor, 2016, [Tuit]) ${ }^{7}$

En resumen, para los ingenieros computacionales Tay es un ejemplo claro y revelador de cómo las máquinas funcionan y procesan cuantiosa y diversa información en segundos. La confusión surge cuando los científicos, pienso en los neurocientíficos, psicólogos cognitivos e ingenieros de la inteligencia artificial, utilizan la evidencia de actividad física, sea de una máquina artificial o humana, para explicar cómo es que una máquina o el hombre piensan. En pocas palabras, extrapolan el registro de la actividad física para asumir que la maquina tiene consciencia tanto del proceso que efectuó como de la información que procesó.

Kosslyn, Thompson y Ganis en su investigación sobre la imagery (2006) señalan que su propósito es explicar cómo es que el hombre genera y usa las imágenes mentales. Sin embargo, la confusión conceptual se hace presente cuando involucran la neurociencia y sus instrumentos para registrar la actividad cerebral mientras los participantes de sus experimentos efectúan tareas cognitivas. Dicha confusión ocurre al describir el registro de la actividad cerebral como si fuera evidencia de cómo el cerebro genera, usa, almacena y transforma imágenes mentales. En otras palabras, cometen una falacia mereológica al sustituir a la persona, al hombre, por el cerebro y atribuirle a este órgano la capacidad de imaginar.

\footnotetext{
${ }^{7}$ Mellor, Gerald. (23 de marzo de 2016). "Tay" went from "humans are super cool" to full nazi in $24 \mathrm{hrs}$ and I'm not at all concerned about the future of Al (Tuit). Recuperado de: https://twitter.com/geraldmellor/status/712880710328139776
} 
En el trabajo que realizaron Kosslyn y Moulton (2009) correlacionan la tarea psicológica con la actividad física. Me explico, les pidieron a los participantes de su experimento que imaginaran un postre y asumieron que conforme realizaban la tarea solicitada (imaginar verlo, comerlo, olerlo) se registraba actividad en las regiones del cerebro involucradas. Estos teóricos respaldan su experimento con resultados obtenidos de investigaciones previas efectuadas por otros teóricos. Señalan Moulton y Kosslyn (2009, p. 1275):

Por ejemplo, mientras los individuos que imaginan preparar una banana split deberían con seguridad activar su corteza visual (y posiblemente su corteza motora), individuos que imaginan la sensación de comer una banana split deberían con seguridad activar su corteza gustativa (y posiblemente su corteza motora). En efecto, hay mucha evidencia que apoya esta afirmación. Las imágenes visuales activan las cortezas visuales, incluyendo, en algunos casos, la corteza temprana (e.g., Kosslyn y Thompson 2003), imágenes auditivas activan la corteza auditiva (e.g. Zatorre et al. 1996), imágenes de acción activan las cortezas motor (e.g. Porro et al. 1996) y las imágenes gustativas activan las cortezas gustativas (e.g. Kobayashi et al. 2004). ${ }^{8}$

A mi juicio, esta explicación es una escandalosa falacia por abducción con la que pretenden correlacionar estados mentales con estados físicos. A continuación presento dos argumentos que objetan la correlación:

1. Señala McGinn (2003, p. 78): "Invito al lector a tratar de concebir una propiedad perceptible del cerebro que pueda disipar el sentimiento de misterio que acompaña nuestra contemplación del eslabón mente-cerebro: no creo que sea capaz de hacerlo. Es como intentar concebir una propiedad perceptible de una roca que mostrara claramente que la roca es consciente".

\footnotetext{
8 "For example, whereas individuals who imagine preparing a banana split should reliably activate their visual cortex (and possibly motor cortex), individuals who imagine the sensation of eating a banana split should reliably activate their gustatory cortex (and possibly motor cortex). Indeed, much evidence supports this claim. Visual imagery activates the visual cortices, including, in some cases, the earliest cortex (e.g. Kosslyn \& Thompson 2003), auditory imagery activates the auditory cortices (e.g. Zatorre et al. 1996), motor imagery activates motor cortices (e.g. Porro et al. 1996) and gustatory imagery activates gustatory cortices" (e.g. Kobayashi et al. 2004).
} 
2. Concuerdo con McGinn, no es posible relacionar las propiedades del cerebro con la consciencia dado que las propiedades de este órgano son espaciales y sus procesos están espacialmente distribuidos mientras que los estados mentales son estados no físicos. Señala McGinn (2003, p. 79):

Los sentidos responden a ciertos tipos de propiedades -las que están ligadas esencialmente con el espacio-, pero esas propiedades pertenecen al tipo incorrecto (a la categoría incorrecta) para constituir $P$. Kant estaba en lo cierto: la forma de nuestra sensibilidad externa es espacial; pero, si ello es así, entonces $P$ será nouménico con respecto a los sentidos, ya que ninguna propiedad espacial proporcionará jamás una respuesta satisfactoria al problema mente-cuerpo.

Me detendré para explicar cuál es la postura de Kant en la Crítica de la razón pura (2000) sobre la consciencia. Si mi lectura es correcta, el objetivo de Kant en la Crítica no es dilucidar la naturaleza de este concepto pero, dado que en el sistema que propone juega un papel fundamental, puedo utilizarlo para mostrar cómo en la psicología se confunde la explicación del proceso del pensamiento con la explicación de otros conceptos, en este caso, la consciencia.

Para Kant, la consciencia es la acción del Yo, el alma, en tanto que nos permite: a) intuir representaciones de las cosas del mundo y b) describir cómo experienciamos lo intuido.

El inciso a consiste en que acompañamos, mediante la figura del Yo o del $a l m a^{9}$ cada una de nuestras representaciones que intuimos. Al respecto Kant (2000) es contundente y concreto. Señala en la Crítica de la razón pura (B 132): "el Yo pienso tiene que poder acompañar todas mis representaciones. De lo contrario sería representado en mí algo que no podría ser pensado, lo que equivale a decir que la representación, o bien sería imposible o, al menos, no sería nada para mí".

El inciso b ocurre cuando reclamo como mío lo que intuyo ("[las intuiciones] me pertenecen", Crítica de la razón pura, 2000, B 134), a fin de que al sintetizar las representaciones sean parte de mi autoconsciencia (Yo pienso), de mi bagaje conceptual. En efecto, Kant (2000, B138)

\footnotetext{
${ }^{9}$ En B399, A 346, B400, A342, B 403, A 345, A 346, A 348, B 400, A 342, B 404, A 346 de la Crítica de la razón pura, Kant describe al Yo o al Alma como una sustancia que tiene las siguientes cualidades: Inmaterial, Incorruptible $y$ Personalidad.
} 
señala: "la unidad sintética de la consciencia es, pues, una condición objetiva de todo conocimiento". Es decir, en Kant, la consciencia no sólo hace posible el conocimiento sino también que el hombre sea capaz de aplicarlo y relacionarlo mediante su talento natural (el juicio).

El funcionamiento del sistema kantiano puede ser visto como un proceso psicológico, es decir, como un proceso interno, oculto y previo en el que sintetizamos la información sensible para "nutrir" el concepto del objeto intuido.

Algo semejante tienen en mente los teóricos de la imagery sobre la consciencia. Hablan de ella como el resultado de un proceso interno, en tanto que en este proceso se compaginan datos de las cosas del mundo provenientes de nuestros sentidos con las "reglas" o "categorías puras" que regulan el "pensamiento" de las máquinas artificiales y humanas (robots, computadoras y cerebros). Bajo esta misma idea, por una confusión conceptual, los investigadores y científicos presuponen que los componentes de las máquinas y del cerebro (procesadores, chips, neurona, corteza cerebral, regiones cerebrales) son las que tienen consciencia, dado que estos son los que realizan los procesos computacionales.

De tal manera que para los científicos la consciencia tiene otro significado por el contexto en el que es empleado el término. Así, la consciencia da cuenta de la capacidad interpretativa de la máquina o del cerebro de los participantes de sus experimentos. Incluso, podría interpretarse que cuando los teóricos hablan de imágenes almacenadas en el cerebro, es decir, de las representaciones del objeto que son manipuladas en el interior de nuestra cabeza, están hablando de manera literal: en nuestro cerebro se encuentran alojadas imágenes mentales cuyo acceso es logrado mediante un evento físico, neural. Un ejemplo de esta confusión conceptual es el trabajo de Chabris y Kosslyn (2006, p. 1) leemos:

En esencia, el análisis es una actividad cognitiva. Aunque los analistas frecuentemente recurren tanto a los instrumentos tecnológicos como a aportaciones de otras áreas, en 
última instancia, es el cerebro humano el que organiza e interpreta los datos para generar una evaluación o predicción. ${ }^{10}$

Siguiendo con Stephen Kosslyn et al, en su libro The Case for Mental Imagery del 2006, dejan claro, a través de una analogía con el funcionamiento de las máquinas, su pretensión (neuropsicológica) de correlacionar eventos neurales, físicos, con estados mentales para explicar cómo el hombre genera y usa imágenes para simular sus acciones. Sostienen estos investigadores (Kosslyn, Thompson y Ganis, 2006, pp. 18-19):

Si tomamos esta conclusión [el cerebro es una máquina y utiliza distintos formatos para la información] para indicar que una imagen o representación delineada en el cerebro [depictive representation] está siendo usada (como deberíamos, dada nuestra caracterización de tal representación), nos lleva a la conclusión que las imágenes mentales no son como puntos en una matriz en una computadora en al menos un aspecto fundamental: cada neurona en esta área visual no simplemente registra la presencia o ausencia de un punto de luz. Sino las neuronas además codifican las propiedades específicas tales como la orientación de los segmentos de línea, tono, y disparidad binocular (lo que es una clave para la profundidad). (Subrayado mío). ${ }^{11}$

\section{Conclusión}

¿Qué entendemos por consciencia?

Primero: Apelemos al consejo de Aristóteles: una manera de aproximarnos sobre el conocimiento de algo es rechazar aquello que no es. De tal manera, descartemos las respuestas que provengan de experimentos que busquen responder cómo el cerebro y las máquinas trabajan, hay que descartarlas

\footnotetext{
10 "At core, analysis is a cognitive activity. Although analysts often draw on both technological aids and input from others, it ultimately is the human brain that organizes and interprets data to generate an assessment or prediction".

11 "If we take this finding to indicate that a depictive representation is being used (as we should, given our characterization of such representation), we are led to conclude that mental images are not like points in an array in a computer in at least one fundamental respect: each neuron in this visual area does not simply register the presence or absence of a point of light. Rather, the neurons also code for specific properties such as the orientation of the line segments, hue, and binocular disparity (which is a cue for depth)".
} 
por la razón de que el propósito de sus evidencias es explicar el funcionamiento físico de una maquina o de un cerebro.

Segundo: Descartemos las explicaciones híbridas en las que se nos hable de que la consciencia es un rasgo natural del cerebro (Chalmers, 1996); por la razón del uso descuidado de los conceptos y porque el propósito no es precisamente explicar lo que entienden los que sostienen estas teorías por consciencia, lo que se persiguen es correlacionar estados físicos con estados mentales.

Tercero: Descartemos las respuestas psicológicas que nos digan que la consciencia es la capacidad del hombre para realizar y darse cuenta del proceso interior que efectúa para dar respuesta a los problemas que enfrenta en su vida, en tanto que dicho proceso es parte de una explicación de cómo funciona nuestra mente. Cabe tener presente que la introspección no es un método confiable para "observar" qué es lo que estamos pensando y cómo lo estamos pensando.

Después de esto, podemos decir que la consciencia consiste en una habilidad humana que permite, a cualquier hombre, explicar qué quiere decir cuando señala que una persona se ha percatado, recordado, observado, comprendido, etc., algo que experimentó en algún momento de su vida o, expresar en primera persona porque qué decimos que somos conscientes de una situación o un hecho que experimentamos.

Si aceptamos estas descripciones, observaremos que el término consciencia no tiene nada que ver con el funcionamiento del cerebro ni con la explicación sobre el funcionamiento de una inteligencia artificial. Sería un sinsentido decir que "S sabe que P" porque los registros de actividad cerebral así lo indican. Esto no tiene nada que ver con el uso que hacemos del término consciencia. ¿Para qué decimos que S sabe que P? Para explicar o describir la conducta de $\mathrm{S}$ al efectuar cierta tarea de manera correcta o incorrecta o bien, mostrar cierta conducta.

Kant en la Introducción: "El Juicio trascendental en general" del Libro Segundo de la Analítica Trascendental de la Crítica de la razón pura (2000) distingue la facultad del juicio de la facultad del entendimiento. De su exposición podemos destacar el papel que tiene el término consciencia para explicar en qué consiste el juicio: "capacidad de distinguir si algo cae o no bajo una regla dada". Y por otro lado, ejemplificar el funcionamiento de un sistema psicológico para, con esto, mostrar el error de 
los teóricos de creer que mediante la explicación del funcionamiento de nuestro pensamiento, podemos explicar en qué consiste la consciencia.

Partamos de la descripción que hace Kant del juicio. Para este filósofo, el juicio es un talento natural del hombre que le permite relacionar y aplicar los conocimientos o conceptos aprendidos, dicho talento, a mi parecer, está relacionado con la consciencia. Como he señalado anteriormente, así lo asume Kant con su categoría trascendental (Yo pienso). Kant lo ejemplifica con un caso ficticio de un estudiante de medicina que, por su formación, ha conformado un bagaje conceptual suficiente para emplearlo en distintos tipos de situaciones médicas. Ahora en el campo laboral ha puesto en práctica ese bagaje conceptual relacionándolo con diversos casos médicos.

La lectura psicológica del caso que expuso Kant consiste en que toda respuesta o conducta se deriva de un proceso interno que ocurre en nuestra cabeza o mente. Ahora, si apelamos a la teoría de imagery, esta teoría señalaría que dicho proceso consiste en recuperar de la memoria los conceptos relacionados con una situación específica y generar, en nuestra cabeza (cerebro/mente) un escenario hipotético en el que podamos emplear dichos conceptos para simular nuestras respuestas y así anticipar las consecuencias de cada una de ellas.

En este caso, el psicólogo haría un esquema funcional para explicar cómo el médico atendió un problema: “el médico recibió información sobre el estado de salud del paciente, 'recuperó' de su memoria los conceptos involucrados y con ellos generó una imagen (mental) en la que simuló su respuesta. Una vez ponderadas las consecuencias (de su respuesta) actuó conforme lo que simuló en su mente/cabeza". En otras palabras, para el psicólogo, el estudiante de medicina primero recibió información y una instrucción, posteriormente "visualizó" la información en su cabeza para generar su respuesta o conducta y respondió a la situación demandada conforme lo que entrenó en el interior de su cabeza.

Pero podríamos explicarlo de otra manera: asumamos que la consciencia es un concepto, una palabra que utilizamos en expresiones del siguiente tipo: "decimos que S está consciente" o "que yo expreso estar consciente de algo" para acompañar situaciones en las que recordamos, observamos, comprendimos, etc. Mientras que el juicio es un término que me permite explicar cómo relaciono conceptos en situaciones que me demandan una respuesta y que significan para mí un reto. Es decir, en 
el lenguaje, en el uso de estos términos, observaremos qué queremos decir con que el médico fue consciente y tuvo la habilidad de relacionar lo aprendido conforme la información e instrucción que le fueron dados. De tal manera que si seguimos el uso del lenguaje, prescindiríamos de la idea de que ocurre un proceso interno, intermedio, entre la recepción de la información (instrucción, datos sensoriales) y la respuesta. Donde este proceso es clave para significar y entender, siguiendo el ejemplo, la conducta del médico. Nos bastaría relacionar lo que se le solicitó y su conducta para explicar, describir lo que queremos decir cuando hablamos de que el médico tuvo consciencia de lo que realizó.

Lo mismo sucede cuando queremos utilizar el término consciencia. Podemos prescindir de las explicaciones de naturaleza física y psicológica de cómo el hombre piensa para concentrarnos en la conducta de los sujetos. Por ejemplo, si digo: “Abraham se percató (tuvo consciencia) del mayor peso filosófico que tiene el por qué (consideramos que las personas deberían saber nuestra perspectiva ética) que el cómo (preocuparnos y ocuparnos por encontrar la mejor manera de transmitir nuestra perspectiva) porque aportó razones que apoyarían la conveniencia de dejar clara nuestra visión ética sobre un problema", estoy explicando a qué me refiero cuando hablo de 'tener consciencia' y muestro que no tendría sentido explicar el proceso interno que ocurre en una persona para significar el término consciencia.

Para Wittgenstein, la idea de señalar un "lugar" en el que ocurre el pensamiento genera confusión en el uso de los términos mente, cerebro, pensamiento, consciencia. Provoca confusión por la razón de que cosificamos los estados mentales y señalamos un órgano físico, el cerebro, como el "lugar" en donde se encuentran. De tal manera que el significado de los verbos psicológicos: pensar, recordar, saber, comprender, etc., es extrapolado por los investigadores de la actividad cerebral en el momento de utilizarlos para describir sus resultados: "el cerebro interpreta, almacena, explora, etc.".

La idea de que la consciencia es el proceso mental en el que generamos imágenes mentales con las que simulamos nuestra respuesta, no es más que un sinsentido en tanto que el proceso es producto de una especulación de cómo es que creemos que pensamos, mientras que el término consciencia demanda una explicación respecto al uso que hacemos de éste cuando queremos dar cuenta de nuestra vida mental. 


\section{Referencias}

Chabris, C.; Jerde, T.; Woolley, A.; Gerbasi, M.; Schuldt, J.; Bennett, S.; Hackman, R.; \& Kosslyn, S. (12 de junio de 2006). Technical Report. Spatial and Object Visualization Cognitive Styles: Validation Studies in 3800 Individuals, No. 2. Recuperado de:

https://www.researchgate.net/publication/238687967_Spatial_and_Object_Visualization_Cogni tive_Styles_Validation_Studies_in_3800_Individuals

Chalmers, D. (1996). The Conscious Mind: In Search of a Fundamental Theory, Nueva York: Oxford University Press.

Kant, I. (2000). Crítica de la razón pura [Traducido al español de Kritik der reinen Vernunft]. Madrid: Alfaguara.

Kosslyn, S. M. y Ochsner, K. N. (1994). Mental Imagery, Universidad de Harvard.

Kosslyn, S. M., Thompson, W. L. y Ganis, G. (2006). The Case for Mental Imagery, Nueva York: Oxford U. Press.

McGinn, C. (2003). “(Can we solve the Mind-Body problem?, 1989) ¿Podemos resolver el problema Mente-Cuerpo?", (trad. Hector Islas) en La naturaleza de la experiencia. Vol. I Sensaciones, Mayte Ezcurdia y Olbeth Hansberg (compiladores), México: UNAM.

Moulton, S. T. y Kosslyn, S. (2009). Imagining predictions: mental imagery as mental emulation, Phil.

Trans. R. Soc. B (2009) 364, Department of Psychology, EU: Universidad de Harvard.

Última vez visitado: 8 de marzo de 2019:

https://royalsocietypublishing.org/doi/full/10.1098/rstb.2008.0314

Nagel T. (2003). “(What is it like to be a bat, 1974) ¿Cómo es ser un murciélago?” en La naturaleza de la experiencia. Vol. I Sensaciones, Maite Ezcurdia y Olbeth Hansberg (compiladores), México: UNAM.

Shanker, S. (1998). Wittgenstein's remarks on the foundations of Al, EU: Routledge. Tomasini, A. (2004). Ensayos de filosofía de la psicología, Guadalajara: Universidad de Guadalajara. 